\title{
Differential Resistance to Botryosphaeria ribis Among Cercis Taxa
}

\author{
M. R. Pooler, USDA/ARS/US National Arboretum, 3501 New York Ave., NE, Washington, DC 20002; K. A. \\ Jacobs, The Morton Arboretum, 4100 Illinois Route 53, Lisle, IL 60532-1293; and M. Kramer, USDA/ARS/BCS, \\ Bldg. 005,10300 Baltimore Ave., Beltsville, MD 20705
}

\begin{abstract}
Pooler, M. R., Jacobs, K. A., and Kramer, M. 2002. Differential resistance to Botryosphaeria ribis among Cercis taxa. Plant Dis. 86:880-882.

The redbud (Cercis sp.) is a popular ornamental small tree or shrub, valued commercially for its early spring bloom and adaptability to diverse environmental conditions. Despite these characteristics, large-scale production of redbud has been limited, due in part to their susceptibility to a fungal canker caused by Botryosphaeria ribis. We screened 711 plants in 11 Cercis taxa for response to inoculation with $B$. ribis. The taxa native to North America, $C$. canadensis and $C$. occidentalis, were more susceptible than Asian species. A logistic regression of the number of symptomatic plants 10 weeks postinoculation with taxa and size (stem diameter) as independent variables explained $41 \%$ of the variation. Sixteen percent was attributable to taxon effects and $36 \%$ was attributable to taxon-independent size effects. Size and taxon effects were not completely orthogonal, and taxa with larger mean stem diameters generally had higher percentages of symptomless plants. A high level of unexplained variation (59\%) was found, and is likely due to intraspecific variation among seed lots. Comparisons of 11 seed lots of $C$. canadensis revealed significantly different proportions of diseased plants ranging from 52 to $92 \%$ after 10 weeks, but all plants eventually became diseased.
\end{abstract}

Additional keywords: Botryosphaeria dothidea, Judas tree

The eastern redbud (Cercis canadensis L.) is a popular woody ornamental plant native to eastern North America that is planted in the landscape chiefly for its showy early spring bloom. The genus Cercis (family Fabaceae) contains, depending on author, 7 to 13 species or subspecies that occur in North America, Europe, and Asia $(4,7,8)$. Species range in size from small shrubs to trees, tolerate full sun to shade, and are hardy in USDA Zones 4 to 9 $(7,9)$. Despite the horticultural merits and wide adaptability of the genus, its use in landscapes is limited due to susceptibility to infection by Botryosphaeria ribis. Breeding programs for Cercis have also been constrained due to the difficulty of propagating clonal material. An important first step in breeding resistant plants is to identify sources of resistance to the pathogen.

Historically, the principal causal agent of this canker disease was identified as either B. dothidea Ces \& De Not. or $B$. ribis Gross. \& Duggar (2). Recent morphological and molecular evidence supports

Corresponding author: M. Pooler

E-mail: mpooler@ars-grin.gov

Accepted for publication 11 April 2002.

Publication no. D-2002-0603-01R

This article is in the public domain and not copyrightable. It may be freely reprinted with customary crediting of the source. The American Phytopathological Society, 2002. differentiating botryosphaeriaceous taxa with Fusicoccum anamorphs into at least two distinct groups. The redbud canker pathogen that is the subject of our study is now confirmed to be $B$. ribis, distinct from B. dothidea $(2,11,12)$.

Preliminary studies suggest that variation exists between and within Cercis species in susceptibility to canker. We hoped to capitalize on this apparent natural variation in resistance by conducting a comprehensive evaluation of several Cercis species. The objective of this study was to identify taxa (or individuals) exhibiting resistance to $B$. ribis.

\section{MATERIALS AND METHODS}

Plant material. Cercis seeds representing 52 seed lots from 11 taxa (Table 1) were purchased, collected at the U.S. National Arboretum in Washington, D.C., or obtained from Index Seminum or the USDA Woody Landscape Plant Germplasm Repository in Glenn Dale, MD. Seeds were scarified by pouring boiling water over seeds, followed by a $24-\mathrm{h}$ soak in the same water, planted in a soilless potting mix (milled sphagnum and Qrok\#4 [1:1]) in flats, and stratified for 3 months at $4^{\circ} \mathrm{C}$ (16). Seed flats were then placed in a greenhouse $\left(21^{\circ} \mathrm{C}\right)$ with supplemental lighting. Seedlings were later transplanted into individual bottomless quart bands in a Metro Mix 510:Perlite (4:1) mixture amended with MicroMax micronutrients. Plant height and stem caliper at $5 \mathrm{~cm}$ above the soil line were measured for each plant at the time of inoculation. One- to two-year-old plants were used in all experiments, with diameters ranging from 0.24 to $1.31 \mathrm{~cm}$ when inoculated. Inoculations took place in late spring to early summer, after plants had leafed out and during active growth. Plants were watered and fertilized as required, and greenhouse temperatures were maintained at 21 to $25^{\circ} \mathrm{C}$ throughout the experiments.

Fungal isolates. Two strains of $B$. ribis were used in the study to avoid using a strain with diminished aggressiveness arising from prolonged storage. Strain 93.03 (ATCC 209922 as B. dothidea) was isolated from a canker on a diseased redbud tree on the grounds of the National Arboretum in Washington, D.C., in 1993 and was used in the first two trials. Strain 98.06 was obtained from a diseased redbud on the grounds of the Morton Arboretum, Lisle, IL, in 1998 and was used in the third and fourth trials. Both strains were isolated from surface-disinfested wood pieces that were excised from underneath cankered bark and placed onto acidified potato dextrose agar (PDA) (Difco Laboratories, Detroit, MI). Working cultures of each strain were stored at $4^{\circ} \mathrm{C}$ in darkness, and backup stock cultures were stored in liquid nitrogen using standard methods (3). Prior to the beginning of each trial, fresh cultures of each strain were made from stock cultures on petri plates of PDA by cutting a 5-mm-diameter mycelial agar plug from the colony margin after 7 to 10 days, inserting the plug into the stem of a redbud sapling in the greenhouse, and after several weeks, reisolating the fungus from the cankered sapling. A fresh colony was grown on PDA and used for experimental inoculations as described below.

Inoculation. Inoculum for the trials consisted of 5-mm-diameter mycelial agar plugs taken from the margins of an actively growing colony on PDA. A 2 to $5 \times 15 \mathrm{~mm}$ vertical flap was cut into the cambium of each plant $5 \mathrm{~cm}$ above the soil line using a sterile scalpel. The inoculum was inserted into the slit so that surface mycelium faced inward. The stem bark was folded back over the plug, and Parafilm was wrapped loosely around the inoculation site. Similarly, control plants (one to three per seed lot) were inoculated with plugs of PDA.

A total of 711 plants were inoculated in four separate trials conducted in adjacent greenhouses at the U.S. National Arboretum. Eleven Cercis taxa, including 20 seed lots of $C$. canadensis, were evaluated. Tri- 
als I and II took place in 1994. Each included 12 plants from one seed lot from six of the taxa listed in Table 1. Trial III took place in 1999 and included 5 to 10 plants from each seed lot for each of the taxa listed in Table 1, including representation of 13 of the $20 \mathrm{C}$. canadensis seed lots. Trial IV started 1 week later than trial III in a separate greenhouse and included 10 to 20 individuals from 16 C. canadensis seed lots, seven of which had not been included in trial III.

Disease monitoring and data analysis. Foliar disease symptoms were rated each week, starting 2 weeks after inoculation. Plants were rated as having symptoms if any of the leaves began wilting and changing color from green to reddish-brown (flagging). Data were collected for at least 12 weeks in all trials except trial III, which ended at 10 weeks due to a cooling failure in the greenhouse that resulted in many plants exhibiting flagging from heat stress. Our analysis is therefore based on whether an individual plant exhibited flagging at 10 weeks (binary dependent variable), testing for the effects of taxon, size (stem diameter when inoculated), and a trial effect using logistic regression (Proc Logistic) (10). The trial effect (trials I and II versus trial III) captures potential differences in symp- tom development due to $B$. ribis isolates (93.03 versus 98.06) and any other variable (e.g., sunlight, water, seed sources) differing between the two sets of trials. Cercis gigantea data are presented for comparison but were excluded from the logistic regression due to small sample size. Data from trial IV were not used for this analysis, as C. canadensis was already adequately represented in trial III and no other species was used in trial IV. Multiple comparisons of the taxa were made using a closed testing procedure (SimTests SAS macro) (15). While one gains considerable power using this procedure, software limitations and replication limitations required us to (i) drop $C$. gigantea and $C$. chingii, represented by 9 and 15 individuals, respectively, from the analysis, and (ii) combine C. chinensis, C. glabra, and C. yunnanensis (as C. chinensis), and C. siliquastrum and $C$. griffithii (as C. siliquastrum). These are natural groupings of closely related species or subspecies (7). We also used the less powerful methodology proposed by Levy (5) to perform multiple comparison tests on the $11 C$. canadensis seed lots (trials III and IV combined) represented by at least 20 individuals, using the proportion of symptomatic plants at 10 weeks as the dependent variable.

Table 1. Number of seed lots, number of plants inoculated with Botryosphaeria ribis, and sources of seeds for taxa in this study

\begin{tabular}{lccl}
\hline Taxa & Seed lots & $\begin{array}{c}\text { Plants } \\
\text { inoculated }\end{array}$ & Sources of seeds ${ }^{\mathbf{z}}$ \\
\hline Cercis canadensis L. & 20 & 336 & IL, MD, PA, DC, MA, NY \\
$\begin{array}{l}\text { C. } \text { canadensis subsp. texensis } \\
\text { C. } \text { chinensis } \text { Bunge }\end{array}$ & 3 & 47 & OK, MD, IL \\
& 6 & 90 & DC, CT, MA, Czechoslovakia, \\
C. chingii Chun & 2 & & Korea \\
C. gigantea Cheng. & 1 & 15 & DC, NC \\
C. glabra Pampanini & 2 & 9 & DC \\
C. griffithii Boiss & 2 & 19 & DC, MD \\
C. occidentalis Torr. & 5 & 48 & DC \\
C. racemosa Oliver & 2 & 42 & DC, MA, MT, OR \\
C. siliquastrum L. & 6 & 48 & Czech., France, Germany, \\
C. yunnanensis Hu et Cheng & 2 & 39 & Netherlands \\
\hline
\end{tabular}

${ }^{\mathrm{z}}$ Seed source (state or country) indicates where seeds were purchased, collected, or obtained through Index Seminum, and not necessarily where the taxa originated; in all cases, the seed was from open-pollinated trees.

\section{RESULTS}

Multiple comparison results for significant differences among taxa are given in Table 2. Cercis racemosa was significantly more resistant 10 weeks after inoculation than any other taxon, and $C$. canadensis and $C$. occidentalis were the most susceptible taxa. Although small sample sizes precluded using $C$. gigantea and $C$. chingii in the multiple comparisons analysis, no $C$. gigantea and only a few $C$. chingii individuals expressed symptoms at 10 weeks, suggesting they are relatively resistant taxa. In general, foliar symptoms began to develop 6 weeks postinoculation. All but two control-inoculated plants, which died due to other causes, had healed over the stem wound site by week 12 and did not develop foliar symptoms.

The stepwise procedure in Proc Logistic using data from the five grouped taxa resulted in a model attributing $41 \%$ of the variation in symptom expression to taxon and size (stem diameter) effects, with larger plants having lower probabilities of exhibiting symptoms. The remaining variation in symptom expression (59\%) was unexplained. The trial effect was not significant $(P=0.11)$, so it is unlikely that the two strains of $B$. ribis differed appreciably in their aggressiveness.

For the logistic regression analyses we used Nagelkerke's (6) adjustment to $R^{2}$ (available in Proc Logistic) as an approximate method of estimating the variation due to taxon and size. The model with both taxon and stem diameter as independent variables explained $41 \%$ of variation in symptom expression, while models with taxon only or stem diameter only as the independent variable explained 16 and $36 \%$ of the variation, respectively. Thus, taxon and size are not orthogonal (independent) variables since $16 \%+36 \%>$ $41 \%$. These results can be interpreted by partitioning the effect of taxon into two components. One component represents taxon differences in mean stem diameter and accounts for $11 \%(=16 \%-5 \%$, see next calculation) of the variation. The other component represents taxon effects other than size, such as inherent differences

Table 2. Proportion of Cercis seedlings from the Botryosphaeria ribis inoculation trials I, II, and III not expressing foliar symptoms 10 weeks after inoculation

\begin{tabular}{|c|c|c|c|c|c|}
\hline Taxon & No. inoculated & $\begin{array}{l}\text { Mean stem diameter } \\
(\mathrm{mm}) \text { and SD }\end{array}$ & $\begin{array}{l}\text { Proportion without } \\
\text { symptoms }\end{array}$ & $\begin{array}{l}\text { No. inoculated or usage in } \\
\text { multiple comparison }\end{array}$ & $\begin{array}{l}\text { Proportion without } \\
\text { symptoms }^{z}\end{array}$ \\
\hline Cercis gigantea & 9 & $8.6(0.9)$ & 1.00 & Not used & \\
\hline C. racemosa & 42 & $9.5(1.9)$ & 0.83 & 42 & $0.83 \mathrm{a}$ \\
\hline C. chingii & 15 & $7.2(0.7)$ & 0.73 & Not used & \\
\hline C. glabra & 19 & $8.5(1.6)$ & 0.63 & With C. chinensis & \\
\hline C. yunnanensis & 39 & $7.8(1.7)$ & 0.62 & With C. chinensis & \\
\hline C. chinensis & 90 & $7.9(1.8)$ & 0.62 & 148 & $0.62 \mathrm{~b}$ \\
\hline C. siliquastrum & 48 & $6.8(2.7)$ & 0.58 & 66 & $0.52 \mathrm{bc}$ \\
\hline C. griffithii & 18 & $5.5(0.9)$ & 0.33 & With $C$. siliquastrum & \\
\hline C. occidentalis & 48 & $6.4(2.5)$ & 0.33 & 48 & $0.33 \mathrm{~cd}$ \\
\hline C. canadensis & 78 & $7.1(1.6)$ & 0.35 & 105 & $0.33 \mathrm{~d}$ \\
\hline C. canadensis subsp. texensis & 27 & $6.2(1.3)$ & 0.26 & With $C$. canadensis & \\
\hline
\end{tabular}

${ }^{\mathrm{z}}$ Letters indicate proportions that are statistically indistinguishable at the $P=0.05$ level using a closed testing procedure (15). The multiple comparison procedure was performed on grouped taxa (indicated in column 5, see text for details), and without $C$. gigantea and $C$. chingii. 
among taxa in resistance, and accounts for $5 \%(=41 \%-36 \%)$ of the variation.

\section{DISCUSSION}

In inoculating over 700 Cercis seedlings from diverse origins with $B$. ribis, we hoped to find some sources of resistance to B. ribis. Certain species, particularly those of Asian origin (C. chinensis, C. chingii, $C$. gigantea, $C$. glabra, and $C$. racemosa), appeared to be more resistant to the disease than $C$. canadensis and other North American Cercis taxa. However, field observations indicate that Asian Cercis species, including $C$. chinensis and $C$. racemosa, can be infected naturally when planted in the United States (K. A. Jacobs, unpublished; 14).

Although all the inoculated plants in this study ultimately died, there was variation within and among taxa in the length of time it took them to wilt, and in trials I and II, in the canker length (data not shown). In preliminary studies, the rate of wilt appeared to be a more sensitive indicator of susceptibility than canker length, as among four seed lots each of $C$. chinensis and $C$. yunnanensis, 10 to $50 \%$ of plants and 24 to $68 \%$ of plants, respectively, wilted, while no significant differences were noted in stem necrosis. Because we were interested in screening a large number of plants in order to identify resistant plants, we used the binary and perhaps more sensitive test of flag versus no flag. However, data on the rate of canker elongation, and pathogen movement within the plant, could still provide important information on possible mechanisms of tolerance in future studies that focus on those species that appear less susceptible to the disease.

We failed to identify a resistant source of $C$. canadensis, as no seed lot yielded completely asymptomatic seedlings and most inoculated $C$. canadensis seedlings became symptomatic by 10 weeks. In these and preliminary studies, $C$. canadensis has consistently appeared to be the most, or among the most, susceptible Cercis species tested (14). Further, although no formal survey has been conducted, we have observed that mature $C$. canadensis in the wild and in landscapes frequently have canker caused by $B$. ribis. Although infected trees continue to live, often for decades, they are slowly disfigured and undoubtedly weakened by the disease. Further studies using seeds gathered from mature trees with little or no canker might prove fruitful, but the probability of find- ing a highly resistant source of Cercis germ plasm appears to be low, especially in light of the fact that only $5 \%$ of the variation in symptom expression could be explained by genetic differences among taxa.

Plant size, as measured by stem diameter, had a significant effect on symptom development as larger plants developed less disease. Size accounted for $36 \%$ of the total variation in symptom expression at 10 weeks postinoculation. It could be interpreted that faster growing, and inherently larger, Cercis species have mechanisms to resist canker better than their smaller counterparts. However, it seems likely that an inoculum dosage effect occurred, as for a given amount of inoculum and equal size wound, smaller plants in these experiments received relatively more fungus. Further studies should utilize a method of inoculation, e.g., injecting stems with a suspension of spores calibrated to a size-dependent concentration to circumvent the dosage issue.

The large percentage $(59 \%)$ of unexplained variation revealed in the logistic regression analyses is not unexpected because diverse seed lots were used to represent a given species, and it is consistent with our results suggesting that considerable intraspecific variation in susceptibility to the pathogen exists. As evidence, the 11 seed lots of $C$. canadensis plants with at least 20 individuals inoculated in trials III and IV exhibited proportions of symptomatic plants ranging from 52 to $92 \%$. However, with the small number of seedlings per seed lot and the large number of comparisons, only the extremes (two seed lots with $92 \%$ and one with $52 \%$ ) differed significantly.

Resistance assays using greenhousegrown juvenile plant material do not always correlate with field data. Our observations of plants in the field and greenhouse suggest that Cercis plants are susceptible to infection by $B$. ribis at all ages. Long-term studies examining this correlation and the ability of Cercis taxa to recover from infection by $B$. ribis are underway.

One strategy for developing resistant plants is to identify taxa (or develop plants) that limit entrance and growth in planta of the pathogen. There are considerable hurdles to overcome, as evidence suggests $B$. ribis and sibling species may be seed transmitted (1) and exhibit endophytic activity (13). Thus, preventing entrance of spores into wounds or lenticels would only partially address the problem. We are currently investigating the possibility of introducing anti-fungal genes into selected taxa in order to confer a high level of resistance.

\section{ACKNOWLEDGMENTS}

This study was supported in part by a grant from the J. Frank Schmidt Family Charitable

Trust. Technical assistance from Ruth Dix and John C. Knowlton, III are gratefully acknowledged.

\section{LITERATURE CITED}

1. Jacobs, K. A. 1996. Presence of Botryosphaeria spp. in redbud seed and efficacy of seed treatments. (Abstr.) Phytopathology 86:S88.

2. Jacobs, K. A. and Rehner, S. A. 1998. Comparison of cultural and morphological characters and ITS sequences in anamorphs of Botryosphaeria and related taxa. Mycologia 90:601-610.

3. Jong, S. C., Dugan, F., and Edwards, M. J., eds. 1996. Filamentous Fungi. Pages 606-608 in: American Type Culture Collection, ATCC, Rockville, MD.

4. Krussmann, G. 1976. Manual of cultivated broad-leaved trees and shrubs. Vol. I, A-D. Timber Press, Beaverton, OR.

5. Levy, K. J. 1977. Pairwise comparisons involving unequal sample sizes associated with correlations, proportions, or variances. Br. J. Math. Stat. Psychol. 30:137-139.

6. Nagelkerke, N. J. D. 1991. A note on a general definition of the coefficient of determination. Biometrika 78:691-692.

7. Raulston, J. C. 1990. Redbud. American Nurseryman 171(5):39-51.

8. Rehder, A. 1990. Manual of Cultivated Trees and Shrubs. 2nd ed. Dioscorides Press, Portland, OR.

9. Robertson, K. R. 1976. Cercis: The redbuds. Arnoldia 36(2):37-49.

10. SAS Institute Inc. 1999. SAS/STAT User's Guide, Version 8. SAS Institute Inc., Cary, NC. pp.1901-2042.

11. Shiguo, Z., Smith, D. R., and Stanosz, G. R. 2001. Differentiation of Botryosphaeria species and related anamorphic fungi using Inter Simple or Short Sequence Repeat (ISSR) fingerprinting. Mycol. Res. 105:919-926.

12. Smith, D. R., and Stanosz, G. R. 2001. Molecular and morphological differentiation of Botryosphaeria dothidea (anamorph Fusicoccum aesculi) from other fungi with Fusicoccum anamorphs. Mycologia 93:505-515.

13. Smith, H., Wingfield, M. J., Coutinho, T., and Crous, P. 1995. Sphaeropsis sapinea and Botryosphaeria dothidea endophytic on pines and eucalypts in South Africa. (Abstr.) Phytopathology 85:1197.

14. Watson, A. J. 1941. Studies of Botryosphaeria ribis on Cercis and Benzoin. Plant Dis. Rep. 25:29-31.

15. Westfall, P. H., Tobias, R. D., Rom, D., Wolfinger, R. D., and Hochberg, Y. 1999. Multiple Comparisons and Multiple Tests Using the SAS System. SAS Institute Inc., Cary, NC.

16. Young, J. A., and Young, C. G. 1992. Cercis L. - Redbud. Pages 96-98 in: Seeds of Woody Plants in North America. Dioscorides Press, Portland, OR. 